Check for updates

Cite this: RSC Adv., 2018, 8, 27623

Received 5th June 2018

Accepted 10th July 2018

DOI: $10.1039 / c 8 r a 04789 h$

rsc.li/rsc-advances

\section{Adsorption characteristics of metal-organic framework MIL-101(Cr) towards sulfamethoxazole and its persulfate oxidation regeneration}

\begin{abstract}
Xiaoli Huang, ${ }^{a}$ Qi Hu, ${ }^{\text {b }}$ Lei Gao, ${ }^{a}$ Qirui Hao, ${ }^{a}$ Peng Wang ${ }^{a}$ and Dongli Qin (D) *a
A metal-organic framework, MIL-101(Cr), was used to adsorb sulfamethoxazole (SMZ) in water and activated persulfate (PS) oxidation was investigated to regenerate SMZ-saturated MIL-101(Cr). Adsorption and oxidation were combined in this study. MIL-101(Cr) was characterized by SEM, BET, XPS and FT-IR analyses. Effects of various operating parameters on adsorption efficiency were studied. The dosages of persulfate for SMZ desorption and oxidation were investigated. The results showed that the recommended $\mathrm{pH}$ was 6-8 for SMZ adsorption and optimum MIL-101(Cr) dosage was $0.1 \mathrm{~g} \mathrm{~L}^{-1}$. SMZ adsorption by $\mathrm{MIL}-101(\mathrm{Cr})$ was a spontaneous process and nearly exothermic. Saturation adsorption capacity was achieved in $180 \mathrm{~s}$ and the adsorption followed the pseudo-second-order model. The maximum adsorption amount of MIL-101(Cr) to SMZ was $181.82 \mathrm{mg} \mathrm{g}^{-1}$ (Langmuir). MIL-101(Cr) also showed good adsorption capacities for sulfachloropyridazine (SCP), sulfamonomethoxine (SMM), and sulfadimethoxine (SDM). Persulfate was helpful for SMZ desorption from the surface of saturated MIL$101(\mathrm{Cr})$ and sufficient persulfate could simultaneously oxidize the SMZ. XPS analysis showed that the structure of MIL-101(Cr) was stable after the persulfate oxidation process. Regenerated MIL-101(Cr) had the same level of adsorption capacity as fresh MIL-101(Cr). An adsorption-oxidation combined process may be set up based on the results. This study provides basic data for the deep treatment of organic micropollutants in urban water bodies.
\end{abstract}

\section{Introduction}

Antibiotics are generally detected in effluents from sewage plants around the World. The discharge of wastewater containing antibiotics has caused great pressure on the natural environment. ${ }^{1}$ Sulfonamides are broad-spectrum antibiotics that are extensively used in fisheries and animal husbandry. The overuse of sulfonamides is not effectively curbed in China, and hence, they are discharged into water sources in large amounts. ${ }^{2}$ As a typical micro-pollutant, even low concentrations of sulfonamides may cause ecotoxicity in water. ${ }^{3}$

In view of increasing antibiotics pollution, numerous methods are being used to remove antibiotics in water, such as biological process, ${ }^{4}$ advanced oxidation process (AOP), ${ }^{5}$ membrane filtration, ${ }^{6}$ electrocoagulation ${ }^{7}$ and adsorption. ${ }^{8}$ Adsorption, compared with biological process and AOP, can directly remove antibiotics from water without large equipment or complex operations. Activated carbon (AC), ${ }^{9}$ several types of biosorbents, clays, zeolites ${ }^{\mathbf{1 0}}$ and metal-organic frameworks (MOFs $)^{11}$ have been developed to remove antibiotics from water.

${ }^{a}$ Heilongjiang River Fisheries Research Institute, Chinese Academy of Fishery Sciences, 150070, Harbin, Heilongjiang, China. E-mail: qdl978@163.com

${ }^{b}$ School of Pharmaceutical Engineering, Shenyang Pharmaceutical University, 110016, Shenyang, Liaoning, China
$\mathrm{AC}$ is a conventional adsorbent in wastewater treatment, but its adsorption capacity for antibiotics is low, particularly at low concentrations. $^{12}$ MOFs are porous materials with threedimensional periodic grid structures formed by metal ion clusters and organic ligands through self-assembly. MOFs have the advantages of high specific surface area, multiple structure composition and open metal sites, and have broad application prospects in the selective adsorption field. They are used to remove aromatic compounds, drug molecules, dye molecules, alcohols and inorganic metal ions from water. ${ }^{13}$ Cychosz et al. compared the stabilities of MOF-5, MOF-177, UMCM-150, MOF505, MOF-100 and HKUST- 1 in the aqueous phase ${ }^{14}$ and finally chose MIL-100 to absorb the pharmaceuticals furosemide and sulfasalazine from water. Tian et al. used functional MOFs to adsorb tetracycline in water and found that the adsorption process conformed to pseudo-second-order kinetics. ${ }^{15}$ Jhung et al. used MOFs to adsorb benzene in water and the equilib-

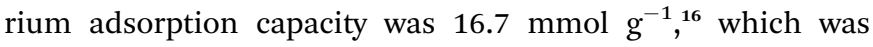
higher than that of AC at $8.0 \mathrm{mmol} \mathrm{g}^{-1}$. Hasan et al. used MOFs to adsorb naproxen and clofibric acid in water, ${ }^{\mathbf{1 7}}$ finding that they had higher adsorption capacities and adsorption rate constants than AC. MOFs exhibits better performance than AC at low concentrations. The adsorption capacity of Zr-MOFs to diclofenac sodium was 13 times higher than that of activated 
carbon. ${ }^{\mathbf{1 2}}$ Therefore, compared to activated carbon, MOFs reflect superior adsorption of micro-pollutants from water.

Adsorption is a convenient way to remove antibiotics from water. However, on saturation, the adsorbents may be regenerated, discarded and replaced by a fresh adsorbent. The discarded saturated adsorbents easily cause secondary pollution and frequently, adsorbent replacement is not economical. Thermal treatment is widely used to regenerate saturated adsorbents, but the process needs high energy, discharges lots of toxic gases, and causes partial irreversible adsorption capability loss (10-15\%). ${ }^{18}$ An alternative technique is oxidative chemical regeneration, which can be performed on site and in situ.

AOP can completely oxidize organics, but it is not costeffective to use AOP to directly remove micro-pollutants in water because the target is difficult to handle and the reaction has low efficiency. The use of AOP for the oxidizing enrichment of contaminants on the surfaces of adsorbents improves the removal efficiency of micro-pollutants in water. In fact, AOP has been used to regenerate saturated adsorbents and simultaneously oxidize the enriched organics. ${ }^{19}$ Persulfate oxidation is a new type of AOP developed in recent years. ${ }^{20}$ Persulfate is solid at room temperature, easy to store and transport, and has high stability and water solubility. Sulfate radical anion $\left(\mathrm{SO}_{4}{ }^{-\bullet}\right)$ can be activated from persulfate by UV, heat, alkali, ultrasound, transition metal ions, etc. ${ }^{21}$ The oxidizing capacity of $\mathrm{SO}_{4}{ }^{-\cdot}$ is close to and even exceeds that of $\cdot \mathrm{OH}$; also, $\mathrm{SO}_{4}{ }^{-\cdot}$ is more stable than $\cdot \mathrm{OH}$. An et al. used $\mathrm{SO}_{4}{ }^{-\cdot}$ to oxidize natural organic matter (NOM) on the surface of saturated activated carbon ${ }^{22}$ and the activated carbon was effectively regenerated. Wei et al. used $\mathrm{SO}_{4}{ }^{-\cdot}$ to rapidly regenerate saturated activated carbon, ${ }^{23}$ and the adsorption capacity of activated carbon did not decrease significantly even after 7 cycles. Hutson et al. studied the effect of persulfate oxidation on the adsorption capacity of activated carbon and found that the loss in adsorption capacity can be compensated by $\mathrm{pH}$ adjustment. ${ }^{24}$

In this study, a metal-organic framework, MIL-101(Cr), was used to adsorb sulfamethoxazole (SMZ) in water. The structure of MIL-101(Cr) was investigated through BET, SEM and XPS. The effects of adsorbent dosage, solution $\mathrm{pH}$ and initial concentration of SMZ were studied. Kinetic and equilibrium isotherm models and thermodynamic parameters were explored to disclose the adsorption process. The adsorption capacity of MIL-101(Cr) towards other sulfonamides was also analyzed. Persulfate was used to regenerate saturated MIL$101(\mathrm{Cr})$ and its dosage for SMZ desorption and oxidation was investigated. XPS analysis was used to detect the structure of MIL-101(Cr) before and after persulfate oxidation.

\section{Materials and methods}

\subsection{Materials}

Sulfamethoxazole (SMZ, 98\%) was purchased from Energy Chemical Technology Co., Ltd. (Shanghai, China). Other sulfonamides, such as sulfadimethoxine (SDM, 98\%), sulfamonomethoxine (SMM, 93\%) and sulfachloropyridazine (SCP, 98\%), were bought from Aladdin Chemistry Co., Ltd (Shanghai,
China). Sodium persulfate $\left(\mathrm{Na}_{2} \mathrm{~S}_{2} \mathrm{O}_{8}, 99 \%\right)$ was purchased from Bodi Chemical Reagents Co., Ltd (Tianjin, China). Chromic nitrate nonahydrate $\left(\mathrm{Cr}\left(\mathrm{NO}_{3}\right)_{3} \cdot 9 \mathrm{H}_{2} \mathrm{O}\right)$, terephthalic acid $\left(\mathrm{H}_{2} \mathrm{BDC}\right)$ and hydrofluoric acid (HF) were of analytical grade and purchased from Sinopharm Chemical Reagent Co., Ltd. Other chemicals were of analytical grade unless otherwise stated.

\subsection{Preparation of MIL-101(Cr)}

MIL-101(Cr) was synthesized according to the published procedure with a slight modification..$^{25}$ Details are as follows. A $48 \mathrm{~mL}$ aqueous solution containing $\mathrm{Cr}\left(\mathrm{NO}_{3}\right)_{3} \cdot 9 \mathrm{H}_{2} \mathrm{O}(4 \mathrm{~g}, 10$ $\mathrm{mmol}$ ) and $\mathrm{H}_{2} \mathrm{BDC}(1.66 \mathrm{~g}, 10 \mathrm{mmol})$ was kept in a polytetrafluoroethylene liner. $\mathrm{HF}\left(0.425 \mathrm{~mL}, 40 \mathrm{wt} \%\right.$ in $\left.\mathrm{H}_{2} \mathrm{O}\right)$ was then added to the aqueous solution, followed by magnetic stirring for 15 minutes and ultrasound mixing for 30 minutes. The polytetrafluoroethylene liner was placed in a small stainless-steel vessel and then moved into an oven. The reaction in the oven was conducted at $210{ }^{\circ} \mathrm{C}$ for $8 \mathrm{~h}$. Next, a solid containing MIL$101(\mathrm{Cr})$ was gathered by centrifugation. It was then washed thrice with DMF and absolute ethanol, in sequence. MIL$101(\mathrm{Cr})$, which was green in color, was obtained as granular crystals.

\subsection{Characterization of MIL-101(Cr)}

The morphology of MIL-101(Cr) was observed under a scanning electron microscope (SEM, SU8010). The surface area was analyzed by a Micromeritics TriStar II 3020. The specific surface area from nitrogen adsorption was calculated through the Brunauer-Emmett-Teller (BET) equation. The pore size distribution was calculated using the Barrett-Joyner-Halenda (BJH) equation. MIL-101(Cr) was analyzed by X-ray diffraction (XRD) before and after MIL-101(Cr) was employed for persulfate oxidation.

\subsection{Adsorption test}

An aqueous solution of SMZ with MIL-101(Cr) was mixed using an oscillator with certain speed (revolutions per minute). The concentrations of SMZ were determined by UV spectroscopy (UV-2450, Shimadzu) at $258 \mathrm{~nm}$. All adsorption tests were conducted at natural $\mathrm{pH}$ unless otherwise stated. For adsorbent dosage experiments, varying MIL-101(Cr) dosage (from 1 to 20 $\mathrm{mg}$ ) was added to $100 \mathrm{~mL} \mathrm{SMZ} \mathrm{solution} \mathrm{with} \mathrm{concentration}$ $10 \mathrm{mg} \mathrm{L}^{-1}$. For $\mathrm{pH}$ experiments, $10 \mathrm{mg}$ MIL-101(Cr) was used to adsorb SMZ (10 $\mathrm{mg} \mathrm{L}^{-1}, 50 \mathrm{~mL}$ ) at $\mathrm{pH}$ varying from 3 to 9 . For salt concentration experiments, $15 \mathrm{mg}$ MIL-101(Cr) and $100 \mathrm{~mL}$ SMZ solution were employed. The SMZ concentration was $10 \mathrm{mg} \mathrm{L}^{-1}$ with salt concentration increasing from 0 to $0.5 \mathrm{~mol} \mathrm{~L}^{-1}$. All experiments were carried out in triplicate and average results are presented.

In kinetic studies, $30 \mathrm{mg}$ MIL-101(Cr) was separately added to $\mathrm{SMZ}$ solutions $(500 \mathrm{~mL})$ with concentrations of 10,50 and $100 \mathrm{mg} \mathrm{L}^{-1}$. Changes in concentration were measured at predefined time points. The adsorption amounts at the predefined time points were determined as follows: 


$$
q_{t}=\frac{\left(C_{\mathrm{o}}-C_{t}\right) V}{m}
$$

where $C_{\mathrm{o}}\left(\mathrm{mg} \mathrm{L}^{-1}\right)$ is the initial concentration, $C_{t}\left(\mathrm{mg} \mathrm{L}^{-1}\right)$ is the concentration at time $t(\mathrm{~s}) \cdot q_{t}\left(\mathrm{mg} \mathrm{g}^{-1}\right)$ is the amount absorbed by MIL-101(Cr) at time $t(\mathrm{~min}), V(\mathrm{~L})$ is the volume of SMZ solution and $m(\mathrm{~g})$ is the weight of MIL-101(Cr).

For isotherm experiments, $15 \mathrm{mg}$ MIL-101(Cr) was added to SMZ solutions (100 mL) varying from 6 to $120 \mathrm{mg} \mathrm{L}^{-1}$ at 25, 35 and $45{ }^{\circ} \mathrm{C}$. The equilibrium data was fitted to the isotherm equations of Langmuir ${ }^{26}$ and Freundlich: ${ }^{27}$

$$
\begin{gathered}
\text { Langmuir : } \frac{C_{\mathrm{e}}}{q_{\mathrm{e}}}=\frac{1}{q_{\max } K_{\mathrm{L}}}+\frac{C_{\mathrm{e}}}{q_{\mathrm{max}}} \\
\text { Freundlich : } \ln q_{\mathrm{e}}=\ln K_{\mathrm{F}}+\frac{1}{n} \ln C_{\mathrm{e}}
\end{gathered}
$$

where $C_{\mathrm{e}}\left(\mathrm{mg} \mathrm{L}^{-1}\right)$ is the equilibrium concentration in solution, $q_{\mathrm{e}}\left(\mathrm{mg} \mathrm{g}^{-1}\right)$ is the equilibrated adsorption capacity of MIL101(Cr), $q_{\max }\left(\mathrm{mg} \mathrm{g}^{-1}\right)$ is the maximum capacity of MIL$101(\mathrm{Cr}), K_{\mathrm{L}}\left(\mathrm{L} \mathrm{g} \mathrm{g}^{-1}\right)$ is the Langmuir isotherm constant, $K_{\mathrm{F}}[(\mathrm{mg}$ $\left.\left.\mathrm{g}^{-1}\right)\left(\mathrm{L} \mathrm{mg}{ }^{-1}\right)^{1 / n}\right]$ is the Freundlich constant, and $1 / n$ is the heterogeneity factor.

\subsection{The desorption by persulfate}

The MIL-101(Cr) adsorbed and saturated by SMZ solution was regenerated in the following process. Twenty milligrams saturated MIL-101(Cr) was desorbed with $200 \mathrm{~mL}$ distilled water for $30 \mathrm{~min}$, followed by the addition of sodium persulfate $\left(\mathrm{Na}_{2} \mathrm{~S}_{2} \mathrm{O}_{8}\right)$ to continue desorption. The persulfate dosage was increased from $0.1 \mathrm{~g}$ to $7.5 \mathrm{~g} \mathrm{~L}^{-1}$. Then, ultrasound was used to activate sodium persulfate to generate $\mathrm{SO}_{4}{ }^{-}$in order to oxidize SMZ both on the surface of MIL-101(Cr) and that desorbed from the MIL-101(Cr) for $45 \mathrm{~min}$. The concentration of SMZ in the mixture was detected by high-performance liquid chromatography (HPLC, LC-20AT, Shimadzu, Co., Ltd, Japan). Finally, MIL-101(Cr) was filtered from the solution and desorbed by methanol $(100 \mathrm{~mL})$ with ultrasound for $30 \mathrm{~min}$. The SMZ concentration in methanol was detected by HPLC. After regeneration by persulfate, MIL-101(Cr) was added to SMZ solution $(100 \mathrm{~mL})$ at a concentration of $15 \mathrm{mg} \mathrm{L}^{-1}$ to test the adsorption amounts.

\section{Results and discussion}

\subsection{Characterization of MIL-101(Cr)}

MIL-101(Cr) was investigated through several characterization methods in this study. The morphology was analyzed by scanning electron microscopy (SEM), as shown in Fig. 1. As shown in the figure, MIL-101(Cr) is an evenly distributed octahedral porous solid with a smooth surface. Most crystals have uniform surface morphologies and some are split or lack angles. A few rod-like particles are mixed with crystals of MIL-101(Cr) (Fig. 1). These rod-like particles might be the recrystallized terephthalic acid $\left(\mathrm{H}_{2} \mathrm{BDC}\right)$ or faulty MIL-101(Cr) crystals.

The BET surface area of MIL-101(Cr) was $2338.31 \mathrm{~m}^{2} \mathrm{~g}^{-1}$, and the average pore size was $2.04 \mathrm{~nm}$ with pore volume of $1.19 \mathrm{~cm}^{3} \mathrm{~g}^{-1}$.

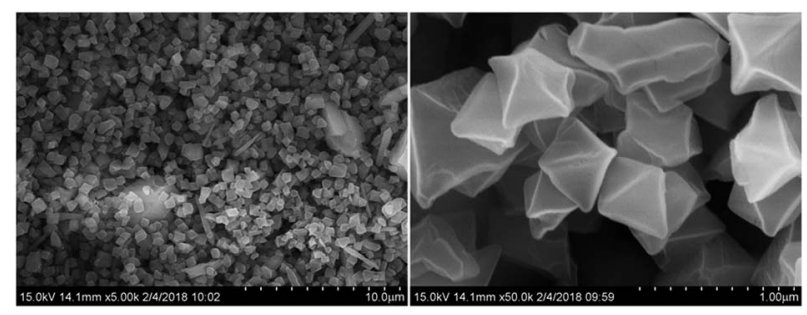

Fig. 1 SEM images of MIL-101(Cr).

The $\mathrm{N}_{2}$ adsorption amount increased quickly when $P / P_{\mathrm{o}}$ was lower than 0.2 (Fig. 2). With $P / P_{\mathrm{o}}$ increasing to 1.0, the $\mathrm{N}_{2}$ adsorption amount increased slightly. The hysteresis loop is not clearly shown in the $\mathrm{N}_{2}$ adsorption-desorption isotherms of MIL-101(Cr). The average pore size $(2.04 \mathrm{~nm})$ could be confirmed from the pore size distribution, as shown in Fig. 2.

X-ray photoelectron spectroscopy (XPS) was used to characterize the Cr oxidation state. Fig. 3 shows the wide-scan and $\mathrm{Cr}$ 2p energy spectra of MIL-101(Cr). The existence of Cr(III) in MIL$101(\mathrm{Cr})$ is evidenced by a shoulder observed on the main peak at $577 \mathrm{eV}$ (Fig. 3b), which is assigned to Cr(III) species.

FT-IR was used to analyze the structure of MIL-101(Cr) before and after SMZ adsorption (Fig. 4). An intense absorption band appeared at $1400-1600 \mathrm{~cm}^{-1}$ in the spectrum, irrespective of adsorption of SMZ by MIL-101(Cr). The band appeared due to $\mathrm{C}-\mathrm{O}$ stretching vibration peak of the benzene ring. The moderate intensity peak at $746 \mathrm{~cm}^{-1}$ is assigned to monosubstituted benzene, and a similar peak at $583 \mathrm{~cm}^{-1}$ is ascribed to $\mathrm{Cr}-\mathrm{O}$ stretching vibration. The FT-IR spectra of MIL$101(\mathrm{Cr})$ before and after adsorption of SMZ were similar in terms of peak shape and location of the peaks. No clear peak appeared at lower wavelengths, and the spectra could not identify the absorption type.

\subsection{Adsorption of SMZ by MIL-101(Cr)}

3.2.1. Effect of different operating conditions. The effect of MIL-101(Cr) dosage on SMZ adsorption was studied at an initial concentration of $10 \mathrm{mg} \mathrm{L}{ }^{-1}$. When the dosage increased from

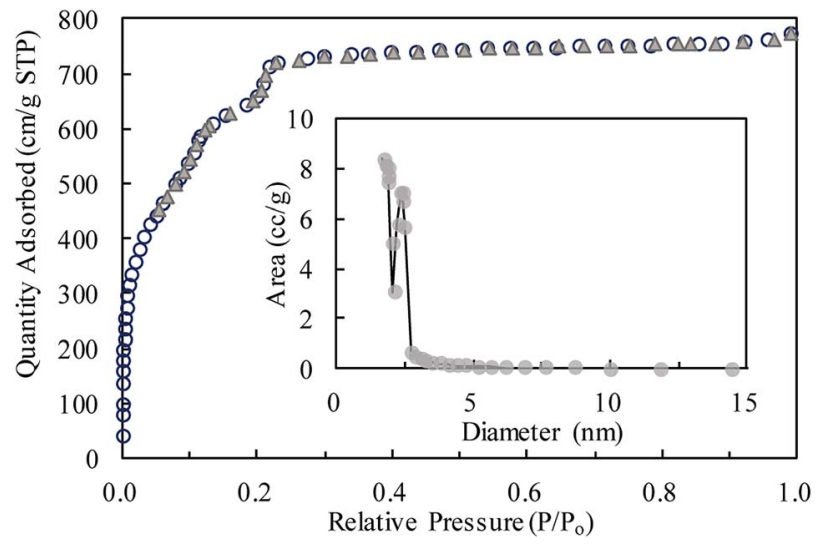

Fig. $2 \mathrm{~N}_{2}$ adsorption-desorption isotherms of MIL-101(Cr). Inset: pore size distribution. 

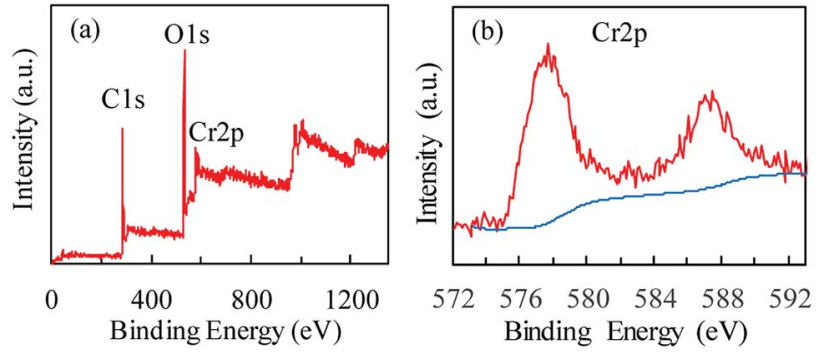

Fig. 3 XPS spectra of MIL-101(Cr): (a) wide-scan, (b) Cr 2p.

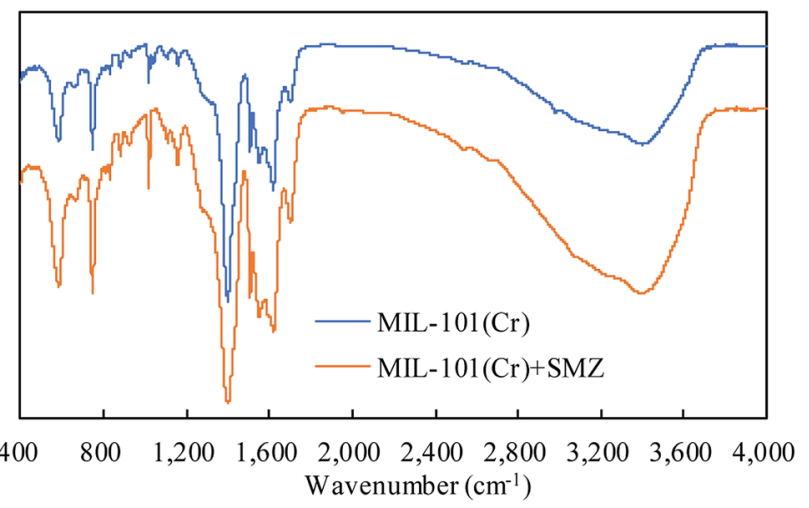

Fig. 4 FT-IR spectra of MIL-101(Cr) before and after adsorption of SMZ.
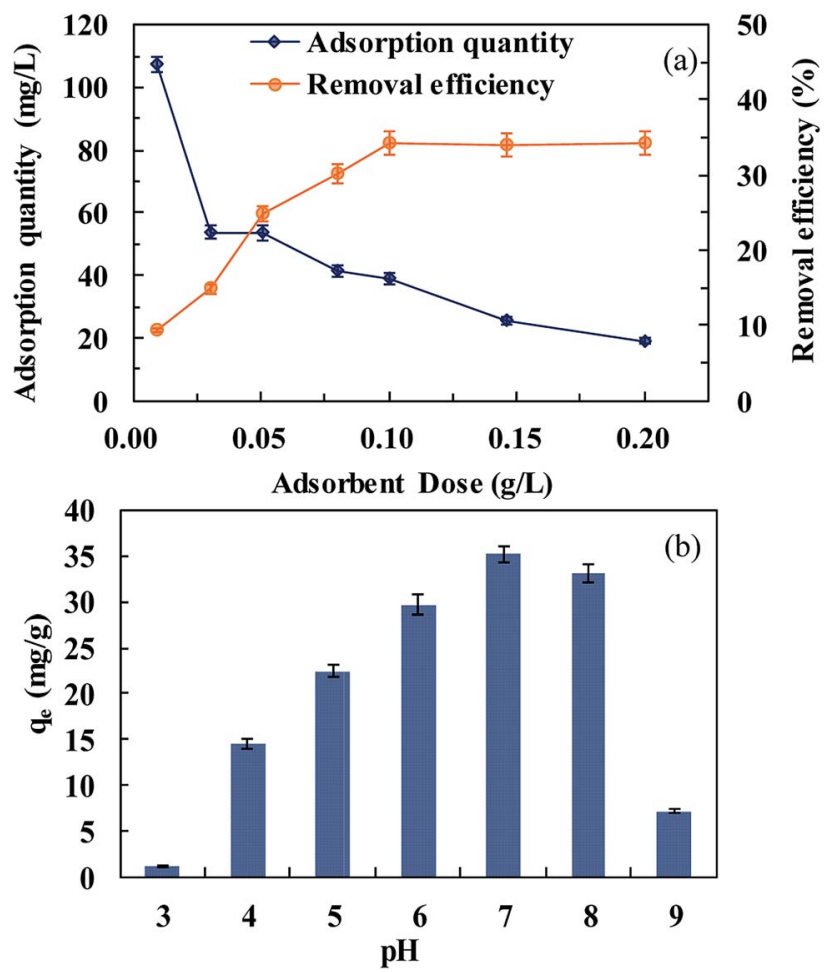

Fig. 5 The effect of adsorbent dosage (a) and pH (b) on SMZ removal by $\mathrm{MIL}-101(\mathrm{Cr})$.
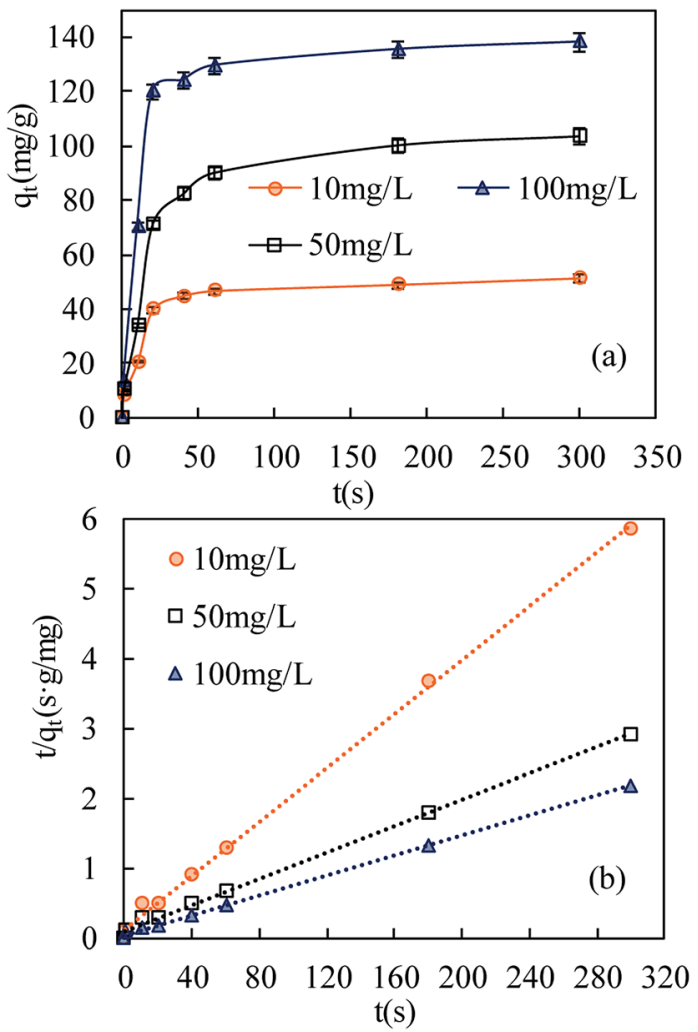

Fig. 6 Adsorption kinetics of SMZ on MIL-101(Cr) at $22^{\circ} \mathrm{C}$ : (a) effect of contact time on SMZ adsorption by MIL-101(Cr); (b) pseudo-secondorder kinetics (initial pH 7.0).

$0.001 \mathrm{~g} \mathrm{~L}^{-1}$ to $0.2 \mathrm{~g} \mathrm{~L}^{-1}$, the adsorption quantity decreased from $107 \mathrm{mg} \mathrm{g}^{-1}$ to $19 \mathrm{mg} \mathrm{g}^{-1}$ (Fig. 5a). At low dosage, the adsorption capacity of MIL-101(Cr) was high because almost all of its adsorptive sites were occupied by excess SMZ molecules. When the dosage was $0.1 \mathrm{~g} \mathrm{~L}^{-1}$, the SMZ removal efficiency began to stabilize.

The effect of solution $\mathrm{pH}$ on $\mathrm{SMZ}$ adsorption was investigated in the $\mathrm{pH}$ range of 3-9. Generally, the adsorption capacity of MIL-101(Cr) was high, in the range of 6-8 (Fig. 5b). At pH 7, the adsorption amount was $35.2 \mathrm{mg}^{-1}$. The adsorption of SMZ decreased in extremely acidic and alkaline environments. Extreme acidity or alkalinity could hasten molecular SMZ conversion to ionic SMZ. At pH less than 7, MIL-101(Cr) was positively charged on adsorption sites due to protonation. ${ }^{28}$ These charged adsorption sites could repel some of the positively charged SMZ. Lower $\mathrm{pH}$ may strengthen electrostatic repulsion. However, at pH more than 8 , the surfaces of MIL101(Cr) and SMZ were both negatively charged. The electrostatic repulsion decreased the SMZ amount adsorbed by MIL101(Cr).

The effect of salt concentration on the adsorption capacity of MIL-101(Cr) toward SMZ was determined in the range of $\mathrm{NaCl}$ concentrations from $0 \mathrm{~mol} \mathrm{~L}^{-1}$ to $0.5 \mathrm{~mol} \mathrm{~L}^{-1}$. SMZ adsorption decreased with the increase in $\mathrm{NaCl}$ concentration. The adsorption capacities were $28.8,13.8,9.6,8.7$ and $2.3 \mathrm{mg} \mathrm{g}^{-1}$ at $\mathrm{NaCl}$ concentrations of $0,0.01,0.1,0.25$ and $0.5 \mathrm{~mol} \mathrm{~L}^{-1}$, 

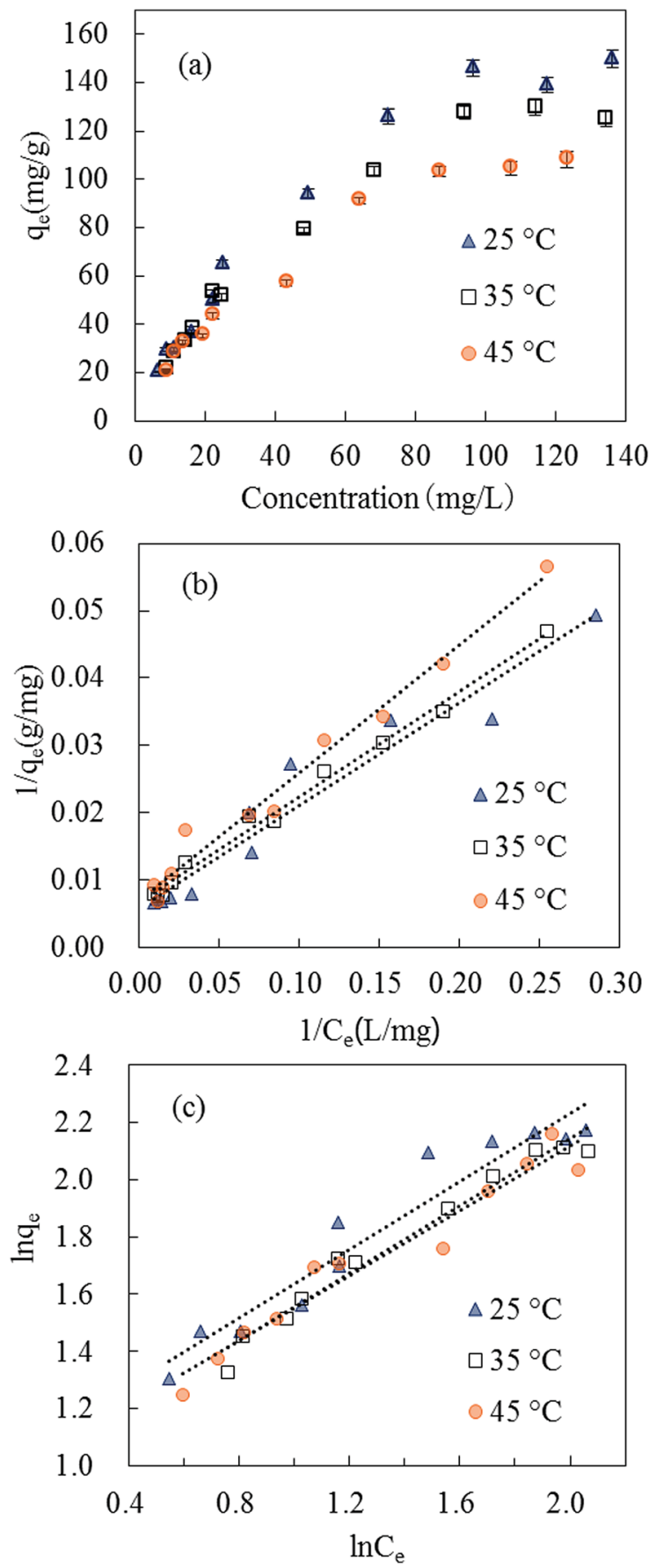

Fig. 7 Isotherm plots of SMZ adsorption on MIL-101(Cr): (a) equilibrium isotherms at 25,35 and $45{ }^{\circ} \mathrm{C}$. (b) The Langmuir adsorption isotherm. (c) The Freundlich adsorption isotherm. respectively. A rise in salt concentration resulted in a decrease in SMZ adsorption. This could be explained by the fact that the adsorption capacity was mainly controlled by electrostatic attraction between SMZ and MIL-101(Cr). Also, high concentration of the cation could compete with SMZ for sites on MIL101(Cr).

3.2.2. Adsorption kinetics. The kinetic behavior of MIL$101(\mathrm{Cr})$ was studied to evaluate the speed of SMZ uptake from water. Generally, the SMZ adsorption equilibrium of MIL$101(\mathrm{Cr})$ was easily reached within a short time (Fig. 6). The adsorbed amount increased quickly during the initial $20 \mathrm{~s}$, and the amount adsorbed at $20 \mathrm{~s}$ reached approximately $80 \%$ of the saturation adsorption capacity (Fig. 6a). The saturation adsorption capacities could be reached within $180 \mathrm{~s}$. The adsorption capacity of MIL-101(Cr) increased with the increase in SMZ concentration.

Pseudo-first-order and pseudo-second-order models were fitted to the data to understand the adsorption kinetics. A high degree of linearity showed that the pseudo-second-order model was applicable for analyzing adsorption kinetics (Fig. 6b). The linear form of the pseudo-second-order model is expressed as follows: ${ }^{29,30}$

$$
\frac{t}{q_{t}}=\frac{1}{k_{2} q_{\mathrm{e}}^{2}}+\frac{1}{q_{\mathrm{e}}} t
$$

where $q_{\mathrm{e}}\left(\mathrm{mg} \mathrm{g}^{-1}\right)$ is the amount of SMZ adsorbed at equilibrium, $q_{t}\left(\mathrm{mg} \mathrm{g}^{-1}\right)$ is the amount at time $t$, and $k_{2}\left[\mathrm{~g}\left(\mathrm{mg}^{-1} \mathrm{~s}^{-1}\right)\right]$ is the pseudo-second-order kinetic adsorption rate constant. The calculated amounts of SMZ adsorbed from the pseudo-secondorder model $\left(q_{\mathrm{e}, \mathrm{cal}}\right)$ agreed with the experimental values $\left(q_{\mathrm{e}, \exp }\right)$. The $q_{\mathrm{e}, \exp }$ values were 51.30, 103.50 and $138.00 \mathrm{mg} \mathrm{g}^{-1}$ at initial concentrations 10,50 and $100 \mathrm{mg} \mathrm{L}^{-1}$, respectively, and the corresponding $q_{\mathrm{e}, \mathrm{cal}}$ values were $52.08,106.38$ and $140.85 \mathrm{mg}$ $\mathrm{g}^{-1}$ with correlation coefficients $\left(R^{2}\right) 0.9982,0.9972$ and 0.9991 , respectively. Based on the results, the pseudo-second-order model fitted the experimental data.

3.2.3. Adsorption isotherms. Adsorption isotherms interpret the specific relationship between adsorbates and adsorbents. Adsorption isotherms were obtained at varying concentrations of SMZ at 25, 35 and $45{ }^{\circ} \mathrm{C}$. The adsorption equilibrium data was fitted to the Freundlich and Langmuir isotherm models, as shown in Fig. 7. Adsorption isotherms and correlation constants obtained from linear analysis are available in Table 1. Both Langmuir and Freundlich isotherm models could describe the experimental data, as exhibited by correlation coefficients $\left(R^{2}\right)$ from 0.9353 to 0.9813 . From Langmuir, the calculated amounts of SMZ adsorbed $\left(q_{\text {max,cal }}\right)$ were

Table 1 Langmuir and Freundlich parameters for SMZ adsorption on MIL-101(Cr) at different temperatures

\begin{tabular}{|c|c|c|c|c|c|c|}
\hline $\begin{array}{l}\text { Temperature } \\
\left({ }^{\circ} \mathrm{C}\right)\end{array}$ & \multicolumn{3}{|l|}{ Langmuir } & \multicolumn{3}{|c|}{ Freundlich } \\
\hline 35 & 181.82 & $2.50 \times 10^{-2}$ & 0.9794 & 1.70 & 2.63 & 0.9696 \\
\hline 45 & 142.86 & $3.69 \times 10^{-2}$ & 0.9813 & 1.77 & 2.68 & 0.9482 \\
\hline
\end{tabular}


Table 2 Comparison of SMZ adsorption capacity of MIL-101(Cr) with other sorbents

\begin{tabular}{lll}
\hline Adsorbents & $q_{\max }\left(\mathrm{mg} \mathrm{g}^{-1}\right)$ & References \\
\hline Silica nanotubes graphene oxide & 125 & 31 \\
Graphene nanosheet & 103 & 32 \\
Graphene- $\mathrm{NH}_{2}$ & 40.6 & 33 \\
Graphene-COOH & 20.5 & 33 \\
Graphene-OH & 11.5 & 33 \\
Rice biochar & 1.83 & 34 \\
Walnut shell & 0.59 & 35 \\
CNT & 21.4 & 36 \\
Propane sulfonate & 155.28 & 37 \\
MIL-101(Cr) & 181.82 & This work
\end{tabular}

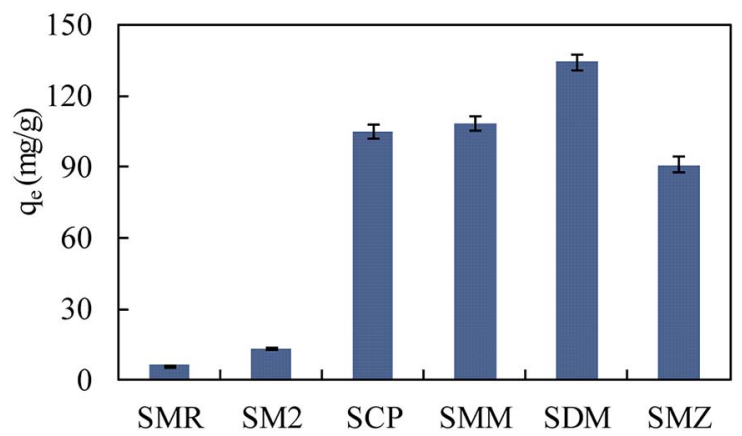

Fig. 8 Comparison of adsorption capacities of MIL-101(Cr) for sulfonamide $\left(50 \mathrm{mg} \mathrm{L}^{-1}, 100 \mathrm{~mL}\right.$ ) removal: sulfamerazine (SMR), sulfadimidine (SM2), sulfachloropyridazine (SCP), sulfamonomethoxine (SMM), sulfadimethoxine (SDM) and sulfamethoxazole (SMZ).

166.67, 181.82 and $142.86 \mathrm{mg} \mathrm{g}^{-1}$ at 25,35 and $45{ }^{\circ} \mathrm{C}$, respectively (Table 1).

The SMZ adsorption capacities of some adsorbents are compared in Table 2. MIL-101(Cr) exhibited strong adsorption ability to SMZ. To investigate the adsorption ability of MIL$101(\mathrm{Cr})$ to more sulfonamides, a fixed amount of adsorbent (15 mg) was used to adsorb sulfamerazine (SMR), sulfadimidine (SM2), sulfamonomethoxine (SMM), sulfachloropyridazine (SCP) and sulfadimethoxine (SDM) in aqueous solutions (volume of solution $=100 \mathrm{~mL}$ ), respectively, at initial concretion $50 \mathrm{mg} \mathrm{L}^{-1}$. The results obtained were compared with $\mathrm{SMZ}$ as in Fig. 8, and MIL-101(Cr) was effective in adsorbing SCP, SMM, SDM and SMZ.

3.2.4. Adsorption thermodynamics. Thermodynamic parameters were used to evaluate the nature of SMZ adsorption by MIL-101(Cr). The standard free energy $\left(\Delta G^{\circ}\right)$, standard entropy $\left(\Delta H^{\mathrm{o}}\right)$, and standard entropy $\left(\Delta S^{\mathrm{o}}\right)$ provided insights into the adsorption behavior of an isolated system, and the calculation was as follows:

$$
\begin{gathered}
\Delta G^{\mathrm{o}}=\Delta H^{\mathrm{o}}-T \Delta S^{\mathrm{o}} \\
\Delta G^{\mathrm{o}}=-R T \ln K \\
\ln K=\frac{\Delta S^{\mathrm{o}}}{R}-\frac{\Delta H^{\mathrm{o}}}{R T}
\end{gathered}
$$

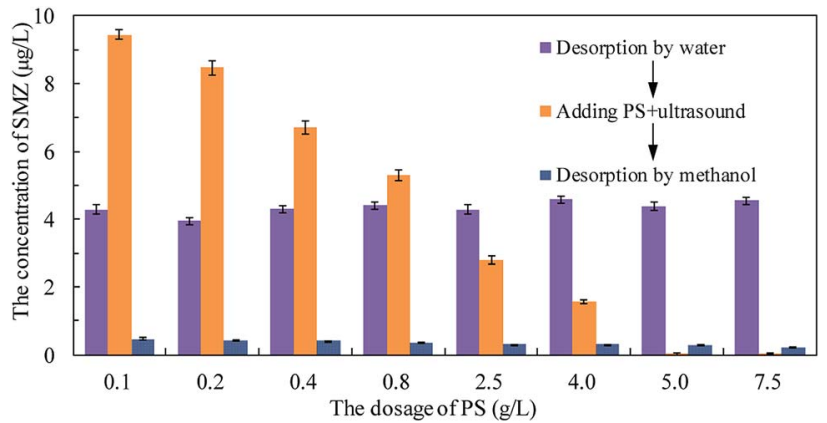

Fig. 9 Desorption of SMZ by different dosages of persulfate.

where $R\left(8.314 \mathrm{~J} \mathrm{~mol}^{-1} \mathrm{~K}^{-1}\right)$ is the gas constant and $T(\mathrm{~K})$ is the Kelvin temperature. $\mathrm{K}$ is the thermodynamic equilibrium constant. $\Delta G^{\mathrm{o}}$ is $-2.312,-1.896$ and $-1.479 \mathrm{~kJ} \mathrm{~mol}^{-1}$ at 25,35 and $45{ }^{\circ} \mathrm{C}$, respectively. The negative values of $\Delta G^{\circ}$ indicate the spontaneity of the adsorption process.

The standard entropy $\left(\Delta H^{\circ}\right)$ was $-14.73 \mathrm{~kJ} \mathrm{~mol}^{-1}$ and the negative value confirmed the exothermic nature of SMZ adsorption by MIL-101(Cr). The standard entropy $\left(\Delta S^{\circ}\right)$ was $-41.65 \mathrm{~J} \mathrm{~K}^{-1} \mathrm{~mol}^{-1}$, which indicated decreasing randomness at the solid-liquid interface. ${ }^{38,39}$ This result could be explained by decreasing collision probability between the adsorbent and reducing SMZ in solution. The system chaos and entropy decreased with the reduction of SMZ in solution.

\subsection{Persulfate oxidation regeneration of MIL-101(Cr)}

Persulfate was used to desorb and oxidize SMZ on the surface of MIL-101(Cr), and thus regenerate the adsorbent. When saturated MIL-101(Cr) was added to an aqueous solution, some SMZ desorbed from the adsorbent and the concentration of SMZ was approximately $4.34 \mu \mathrm{g} \mathrm{L}^{-1}$. Persulfate was added to the solution and ultrasound was used to activate the persulfate to produce sulfate radical anion $\left(\mathrm{SO}_{4}{ }^{-\bullet}\right)$. A low dosage of persulfate could not provide enough $\mathrm{SO}_{4}{ }^{-\cdot}$ to oxidize $\mathrm{SMZ}$, but it accelerated the desorption process. After adding $0.1 \mathrm{~g} \mathrm{~L}^{-1}$ persulfate to the aqueous solution, the SMZ concentration increased from approximately $4.34 \mu \mathrm{g} \mathrm{L}^{-1}$ to $9.43 \mu \mathrm{g} \mathrm{L} \mathrm{L}^{-1}$ (Fig. 9). With the increase in persulfate dosage, the SMZ in solution was gradually oxidized by $\mathrm{SO}_{4}{ }^{-\cdot}$ and thus, the concentration of $\mathrm{SMZ}$ decreased. At the dosage of $5 \mathrm{~g} \mathrm{~L}^{-1}$, the $\mathrm{SMZ}$ concentration decreased to $0.02 \mu \mathrm{g} \mathrm{L}^{-1}$. When the dosage was increased to $7.5 \mathrm{~g} \mathrm{~L}^{-1}$, the SMZ concentration remained at $0.02 \mu \mathrm{g} \mathrm{L}^{-1}$, and SMZ removal was relatively stable. Methanol $(100 \mathrm{~mL})$ was used to treat MIL-101(Cr) that had been oxidized by persulfate. The SMZ remaining on the surface of MIL-101(Cr) was desorbed by methanol, and the SMZ concentration in methanol decreased

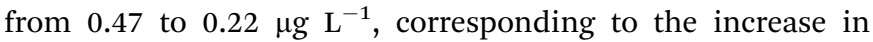
persulfate dosage from 0.1 to $7.5 \mathrm{~g} \mathrm{~L}^{-1}$ (Fig. 9). The methanol desorption process and low SMZ concentration in methanol showed that most of the SMZ on the surface of MIL-101(Cr) was desorbed by persulfate and even a low concentration of persulfate could effectively desorb SMZ.

In order to detect the adsorption ability of MIL-101(Cr) after persulfate oxidation, regenerated MIL-101(Cr) was again used to 


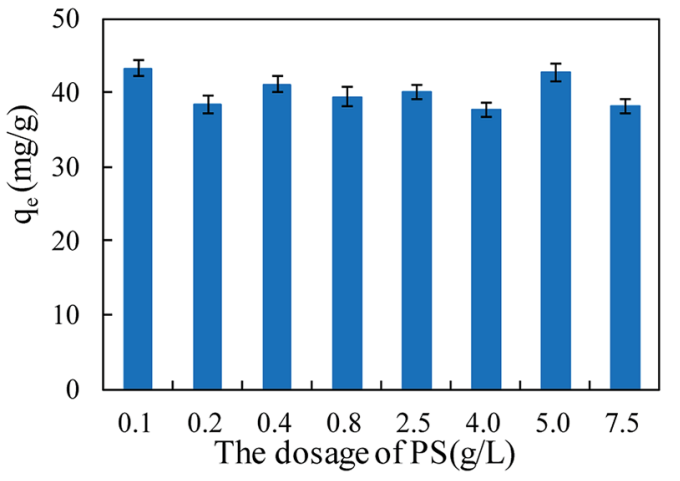

Fig. 10 The adsorption amount of MIL-101(Cr) during re-adsorption process after regeneration by persulfate (PS).

adsorb SMZ. The equilibrium adsorption value was stable at $40.1 \pm 2.1 \mathrm{mg} \mathrm{g}^{-1}$ (Fig. 10), while the value for the fresh adsorbent was $39.8 \pm 1.4 \mathrm{mg} \mathrm{g}^{-1}$. An increase in persulfate dosage during oxidation did not damage the adsorption ability of MIL-101(Cr). The change in adsorption value was not significant when the dosage increased from 0.1 to $7.5 \mathrm{~g} \mathrm{~L}^{-1}$ (Fig. 10). XPS spectra of MIL-101(Cr) before and after treatment with persulfate are shown in Fig. 11. The peaks that appearing in fresh MIL-101(Cr) and the regenerated MIL-101(Cr) were almost at the same positions, as shown in the wide-scan and $\mathrm{Cr}$ $2 \mathrm{p}$ spectra. These results can indicate that the structure of MIL$101(\mathrm{Cr})$ is stable during the process of persulfate oxidation.

\subsection{The combination of adsorption and persulfate oxidation}

Fe-based MOF MIL-101(Fe) has been used to activate persulfate in degrading dyes, ${ }^{40}$ and also shows stable structure of MIL-101. In fact, pure MOF catalyst mostly possesses only $\mathrm{Fe}(\mathrm{III})$ and thus, the catalytic activity is weak. In this study, MIL-101(Cr) had larger adsorption capacity to sulfonamides than MIL-101(Fe) under the same conditions. Hydrophobic interactions exist between MIL-101(Cr) and sulfonamides. The $\mathrm{C}=\mathrm{O}$ on MIL101(Cr) could form $-\mathrm{C}=\mathrm{O} \cdots \mathrm{H}-\mathrm{NH}-$ hydrogen bonds with hydrogen atoms of sulfonamides. The hydrogen atoms of free carboxyl on MIL-101(Cr) interacted with nitrogen on sulfonamides' amino groups, and $-\mathrm{COOH} \cdots \mathrm{N}-\mathrm{H}_{2}$-hydrogen bonds were formed. The adsorption capacities of MIL-101(Fe) to sulfamerazine (SMR), sulfadimidine (SM2), sulfachloropyridazine (SCP), sulfamonomethoxine (SMM), sulfadimethoxine (SDM) and sulfamethoxazole (SMZ) were $23.08 \pm 0.48,26.92 \pm 0.67$,
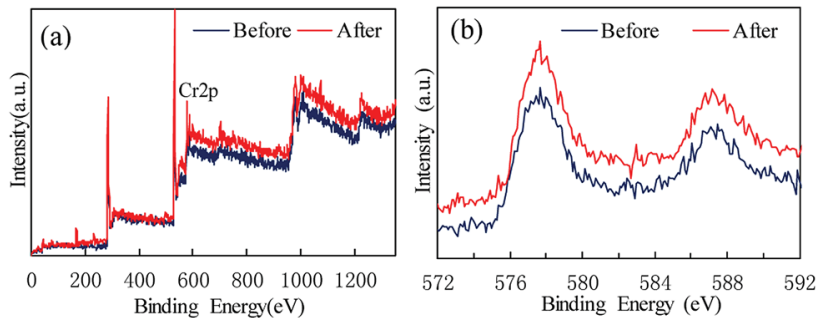

Fig. 11 XPS spectra of MIL-101(Cr) before and after treatment with persulfate: (a) wide-scan, (b) $\mathrm{Cr} 2 \mathrm{p}$.

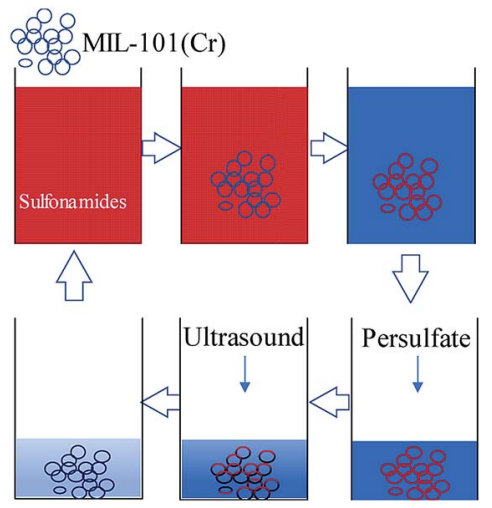

Fig. 12 The combined adsorption and persulfate oxidation process.

$0.93 \pm 0.03,39.46 \pm 1.14,2.72 \pm 0.05,10.33 \pm 0.25 \mathrm{mg} \mathrm{g}^{-1}$, respectively, at $50 \mathrm{mg} \mathrm{L}^{-1}(100 \mathrm{~mL})$. The values of MIL-101(Cr) to SMR, SM2, SCP, SMM, SDM and SMZ were $6.31 \pm 0.15,13.17 \pm$ $0.33,105.15 \pm 2.8,108.24 \pm 2.7,134.05 \pm 3.5$, and $91.12 \pm$ $3.4 \mathrm{mg} \mathrm{g}^{-1}$, respectively. Based on the excellent performances of sulfonamide adsorption and the stable structure of MIL101(Cr), persulfate oxidation has proved to be a promising method for on-site and in situ adsorbent regeneration.

MIL-101(Cr) has excellent adsorption performance towards sulfonamide antibiotics. The activated persulfate is also popular because of its good oxidation capacity. The abovementioned results show that activated persulfate can regenerate MIL101(Cr). Thus, MIL-101(Cr) can be used to adsorb sulfonamides in water and activated persulfate can be used to oxidize the enriched antibiotic to regenerate the adsorbent (Fig. 12). An adsorption-oxidation combined process may be set up by exploring process parameters under different activation conditions. This study provides data support for the extensive treatment of organic micropollutants in urban water bodies.

\section{Conclusions}

In this study, MIL-101(Cr) was used to adsorb SMZ in water. The application of persulfate in regenerating SMZ-saturated MIL$101(\mathrm{Cr})$ was investigated. MIL-101(Cr) was an evenly distributed octahedral porous solid with a smooth surface. MIL101(Cr) showed good adsorption capacity for SMZ at pH 6-8, and the optimum dosage was $0.1 \mathrm{~g} \mathrm{~L}^{-1}$. Salt inhibited SMZ adsorption, particularly at high concentrations. Adsorption reached equilibrium in $180 \mathrm{~s}$ and followed the pseudo-secondorder model. SMZ adsorption followed the Langmuir adsorption isotherm, with adsorption capacities ranging from 142.86 to $181.82 \mathrm{mg} \mathrm{g}^{-1}$. SMZ adsorption by MIL-101(Cr) was a spontaneous and exothermic process. MIL-101(Cr) had equal or better adsorption performance to SCP, SMM and SDM. Persulfate oxidation regeneration was effective in SMZ desorption, and sufficient persulfate could both desorb and oxidize the SMZ simultaneously. No visible structural damage was revealed by the XPS spectra of MIL-101(Cr) after the oxidation process. The regenerated MIL-101(Cr) had the capacity of adsorbing SMZ equivalent to that of the fresh MIL-101(Cr). 


\section{Conflicts of interest}

There are no conflicts to declare.

\section{Acknowledgements}

This research was supported the Special Fund for Agro-scientific Research in the Public Interest (201503108) and the Centrallevel Nonprofit Scientific Research Institutes Special Funds (HSY201606, 2018HY-ZD0604).

\section{Notes and references}

1 K. Kümmerer, Chemosphere, 2009, 75, 417-434.

2 Z. Wang, X.-H. Zhang, Y. Huang and H. Wang, Environ. Pollut., 2015, 204, 223-232.

3 Z. He, X. Cheng, G. Z. Kyzas and J. Fu, J. Mol. Liq., 2016, 223, 781-789.

4 Y. Y. Jia, S. K. Khanal, H. Q. Zhang, G. H. Chen and H. Lu, Water Res., 2017, 119, 12-20.

5 H. Yang, S. Zhuang, Q. Hu, L. T. Hu, L. P. Yang, C. T. Au and B. Yi, Chem. Eng. J., 2018, 339, 32-41.

6 A. Fenu, B. M. R. Donckels, T. Beffa, C. Bemfohr and M. Weemaes, Water Sci. Technol., 2015, 72, 1754-1761.

7 A. Pandiarajan, R. Kamaraj and S. Vasudevan, New J. Chem., 2017, 41, 4518-4530.

8 M. B. Ahmed, J. L. Zhou, H. H. Ngo, W. Guo, M. A. H. Johir and K. Sornalingam, Chem. Eng. J., 2017, 311, 348-358.

9 Q. D. Qin, X. Wu, L. W. Chen, Z. S. Jiang and Y. Xu, RSC Adv., 2018, 8, 1744-1752.

10 G. Z. Kyzas, J. Fu, N. K. Lazaridis, D. N. Bikiaris and K. A. Matis, J. Mol. Liq., 2015, 209, 87-93.

11 B. Wang, X. L. Lv, D. W. Feng, L. H. Xie, J. Zhang, M. Li, Y. B. Xie, J. R. Li and H. C. Zhou, J. Am. Chem. Soc., 2016, 138, 6204-6216.

12 Z. Hasan, N. A. Khan and S. H. Jhung, Chem. Eng. J., 2016, 284, 1406-1413.

13 Z. Hasan and S. H. Jhung, J. Hazard. Mater., 2015, 283, 329339.

14 K. A. Cychosz and A. J. Matzger, Langmuir, 2010, 26, 1719817202.

15 N. Tian, Q. Jia, H. Su, Y. Zhi, A. Ma, J. Wu and S. Shan, J. Porous Mater., 2016, 23, 1269-1278.

16 S. H. Jhung, J. H. Lee, J. W. Yoon, C. Serre, G. Férey and J. S. Chang, Adv. Mater., 2006, 19, 121-124.

17 Z. Hasan, J. Jeon and S. H. Jhung, J. Hazard. Mater., 2012, 209-210, 151-157.

18 X. Huang, D. An, J. Song, W. Gao and Y. Shen, J. Cleaner Prod., 2017, 165, 637-644.
19 A. Cabrera-Codony, R. Gonzalez-Olmos and M. J. Martín, J. Hazard. Mater., 2015, 285, 501-508.

20 I. A. Ike, K. G. Linden, J. D. Orbell and M. Duke, Chem. Eng. J., 2018, 338, 651-669.

21 S. Wacławek, H. V. Lutze, K. Grübel, V. V. T. Padil, M. Černík and D. D. Dionysiou, Chem. Eng. J., 2017, 330, 44-62.

22 D. An, P. Westerhoff, M. Zheng, M. Wu, Y. Yang and C.-A. Chiu, Water Res., 2015, 73, 304-310.

23 M.-C. Wei, K.-S. Wang, I. C. Lin, T.-E. Hsiao, Y.-N. Lin, C.-T. Tang, J.-C. Chen and S.-H. Chang, Chem. Eng. J., 2012, 193-194, 366-371.

24 A. Hutson, S. Ko and S. G. Huling, Chemosphere, 2012, 89, 1218-1223.

25 G. Férey, C. Mellot-Draznieks, C. Serre, F. Millange, J. Dutour, S. Surblé and I. Margiolaki, Science, 2005, 309, 2040-2042.

26 M. Naushad, S. Vasudevan, G. Sharma, A. Kumar and Z. A. Alothman, Desalin. Water Treat., 2016, 57, 18551-18559.

27 R. Kamaraj and S. Vasudevan, Res. Chem. Intermed., 2016, 42, 4077-4095.

28 X. Zhao, Y. Wei, H. Zhao, Z. Gao, Y. Zhang, L. Zhi, Y. Wang and H. Huang, J. Colloid Interface Sci., 2018, 514, 234-239.

29 P. Ganesan, R. Kamaraj, G. Sozhan and S. Vasudevan, Environ. Sci. Pollut. Res., 2013, 20, 987-996.

30 S. Vasudevan and J. Lakshmi, Environ. Eng. Sci., 2012, 29, 563-572.

31 S. O. Akpotu and B. Moodley, ACS Sustainable Chem. Eng., 2018, 6, 4539-4548.

32 R. Rostamian and H. Behnejad, Process Saf. Environ. Prot., 2016, 102, 20-29.

33 H. Chen, B. Gao and H. Li, J. Environ. Chem. Eng., 2014, 2, 310-315.

34 X. Han, C. F. Liang, T. Q. Li, K. Wang, H. G. Huang and X. E. Yang, J. Zhejiang Univ., Sci., B, 2013, 14, 640-649.

35 S. Teixeira, C. Delerue-Matos and L. Santos, Environ. Sci. Pollut. Res., 2012, 19, 3096-3106.

36 B. Chen, W. L. Sun, C. H. Wang and X. Y. Guo, Chem. Eng. J., 2017, 316, 160-170.

37 L. F. Lu, M. L. Gao, Z. Gu, S. F. Yang and Y. N. Liu, J. Environ. Sci., 2014, 26, 2535-2545.

38 R. Kamaraj, A. Pandiarajan, S. Jayakiruba, M. Naushad and S. Vasudevan, J. Mol. Liq., 2016, 215, 204-211.

39 S. Vasudevan, J. Lakshmi and G. Sozhan, Water Environ. Res., 2012, 84, 209-219.

40 X. Li, W. Guo, Z. Liu, R. Wang and H. Liu, Appl. Surf. Sci., 2016, 369, 130-136. 